\title{
Las rieopìs y el mundo andino
}

Por: Luis Enrique Alvizuri

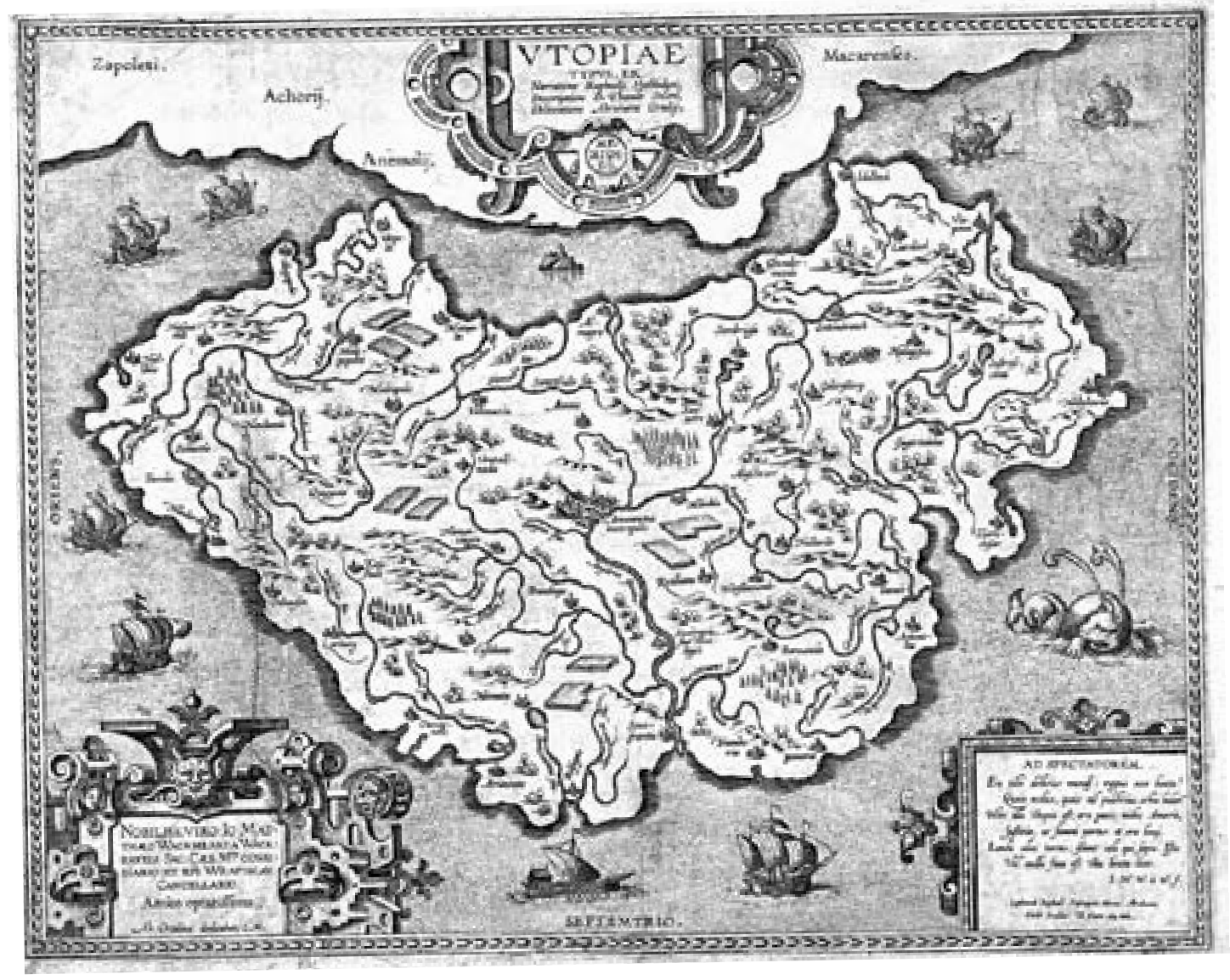

El siguiente es un ensayo acerca de un tema propuesto para desarrollarse en una sesión de los llamados "Cafés filosóficos" organizados por la Asociación de Filosofía Búho Rojo de Lima, Perú. Fue escogido en la forma que dicha entidad acostumbra: mediante la elección por mayoría simple de una de las propuestas hechas por alguno de los asistentes a cada sesión. El tema escogido fue ¿Es posible una utopia peruana? La mecánica consiste en la exposición del mismo en no más de una hora, a lo cual le siguen dos rondas de comentarios y preguntas.

Palabras claves: utopía, cultura, familia, social, sicológico, teoria, conducta humana, seres humanos, hombre, futuro. 


\section{Acerca de la utopía}

La palabra utopía nace con la novela Utopia ${ }^{l}$ escrita por el sacerdote, mártir y santo inglés Tomás Moro en 1516, quien la creó utilizando los términos griegos eutopos que significan "sin lugar". En ella narra lo que ficticiamente el autor vio en una isla lejana, de cómo sus habitantes vivían en un casi perfecto orden y armonía. Su finalidad era hacer una crítica a su sociedad y a su tiempo, anticipando ideas de corte liberal pero en una forma literaria. Pese al trágico final de Moro, el tiempo se ha encargado de reivindicarlo a través de su obra, y hoy tenemos que, dicho título, Utopia, ha devenido en ser un concepto con muchos significados, entre los cuales citamos:

- En su acepción más común, como se maneja popularmente, utopía es un sinónimo de imposible desde todo punto de vista y bajo ninguna circunstancia.

- Desde un punto de vista más académico, son visiones a largo plazo, plantillas, modelos, sueños irreales pero ideales, paradigmas, estímulos coyunturales, shocks extremistas que apuntan a establecer nuevas reglas, fuerzas movilizadoras, reflejos del pasado en el presente que se proyectan hacia el futuro, imágenes de ese futuro, verdades prematuras, esquemas ortodoxos que pueden llevar al fanatismo. (Hacemos notar aquí que, a pesar de existir grandes similitudes entre utopía y mito, asumimos este último como una base, un sustento que conforma la realidad, pero no necesariamente un generador de cambio).

Al llegar a este punto nos preguntamos: ¿Es lo utópico una noción netamente occidental o es común a toda la humanidad? Si no fuese por la creación de Tomás Moro, ¿existiría la utopía tal como la hemos definido hace un momento? Nos inclinamos a pensar que sí. Porque ¿acaso en la historia de los distintos pueblos de la tierra no se han dado esos estímulos movilizadores, aunque no se llamen utopías? Un repaso por los mitos, leyendas y relatos antiguos nos hace ver que todas las agrupaciones humanas tenemos eso en común. Nuestra multiplicación y desplazamiento por todo el planeta parece que no es solo producto de la casualidad. No solo Cristóbal Colón o Marco Polo han sido los únicos hombres empujados por causas utópicas sino muchos más, desde épocas pretéritas y en distintas civilizaciones.

1 https://historia1imagen.files.wordpress.com/2009/08/morotomasutopia.pdf
En cada aventurero, en cada conquistador siempre se halla el sueño del ir más allá. Y si consideramos que el hombre, antes de ser sedentario, fue nómada, con mayor razón, pues es casi inherente al nomadismo tener una concepción del "ir hacia", de prefijar en la mente un destino hacia el cual encaminarse. Cierto que esto es un supuesto indemostrable, pero puede explicarnos muchas cosas acerca de los orígenes de nuestra expansión como especie.

Por otra parte, ¿es la utopía un fenómeno exclusivamente colectivo o puede tener variables? ¿Cuántas lecturas o interpretaciones pueden tener una misma utopía? Lo que queremos plantear es una propuesta para entender el fenómeno utópico, no solo desde su ámbito más común, el colectivo, sino también como suceso particular que puede ser tanto individual como grupal; es decir, que tal vez las utopías pueden manifestarse en distintas proporciones y cantidades de hombres. Visto así, la utopía no se ceñiría a ser un fenómeno eminentemente social sino también sicológico. Solamente para darnos una idea de las posibilidades de este razonamiento haremos mención a unas posibles variables, sin pretender con ello agotar el tema.

\section{Categorías de utopías}

\section{Utopías individuales}

Son aquellas que tienen por sustento el sueño individual. Todas las personas vivimos con una o unas utopías personales las cuales tienen origen en la interacción entre lo adquirido socialmente a través de la familia, la educación, el nivel social, el pueblo, la nación, etc. y lo creado individualmente de acuerdo con nuestra propia historia personal (nuestras inclinaciones, habilidades, defectos, accidentes, traumas, etc.). Esas utopías probablemente nos acompañen toda la vida y sean determinantes a la hora de tomar las decisiones más importantes. Ellas serían el origen de los deseos, los ideales, las ambiciones, que son las que nos impulsan o arrastran a hacer determinadas acciones. En resumen, ellas determinan nuestra vida. Habrá quien el hambre vivido en su infancia lo empuje a la opulencia; otro que se impulse sobre su deseo de reivindicación, de venganza; y también quien lo haga sobre su afán de ser el más poderoso, el más admirado, el más querido, el más reconocido. Todos así estaríamos persiguiendo sueños utópicos, la mayoría de ellos inalcanzables puesto que, hasta los que parecen haberlos logrado, tienen sus aspiraciones puestas en lugares más inaccesibles. Tendríamos que profundizar aún más sobre estas ideas; tal vez descubriríamos cómo se forma y actúa el 


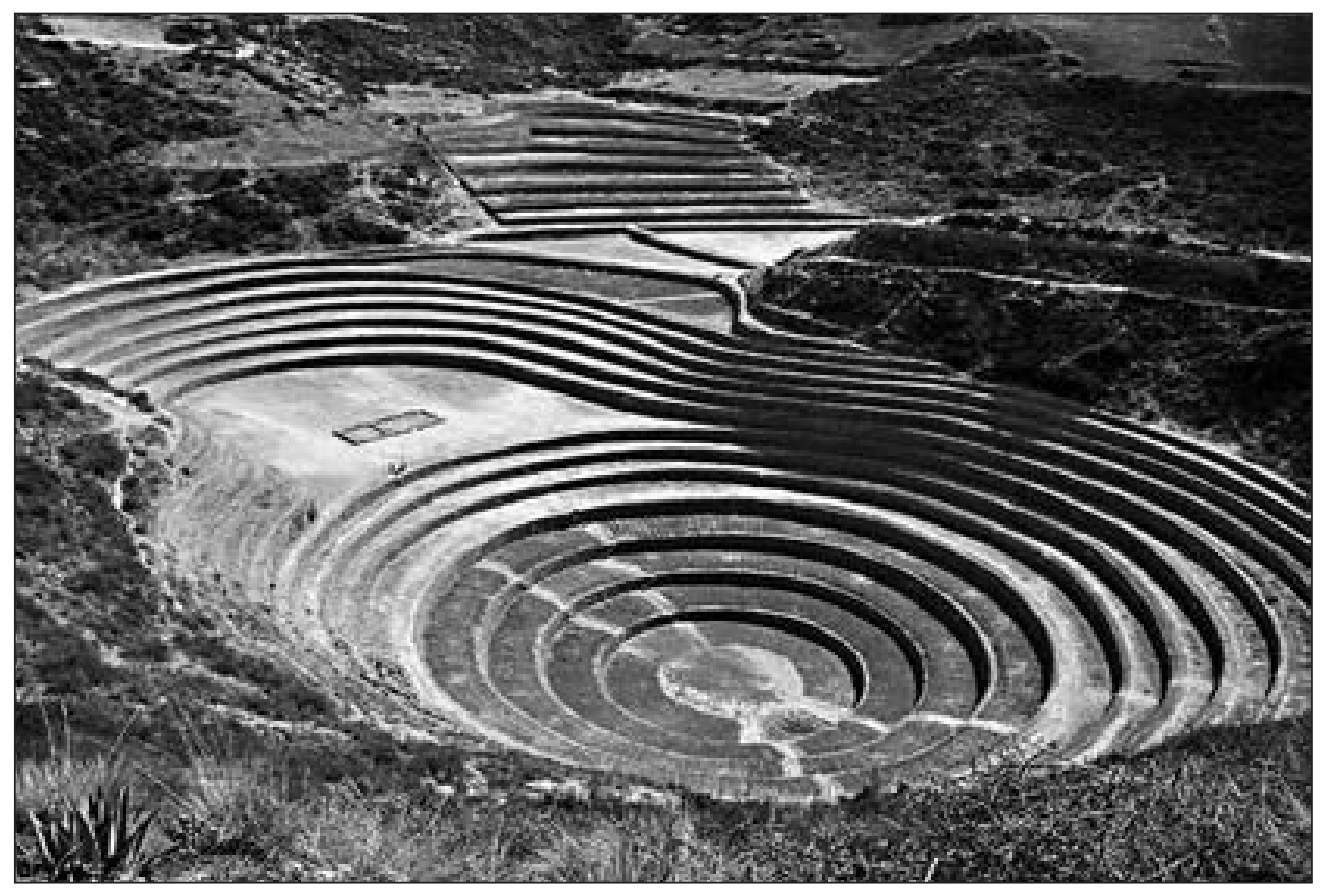

Agricultura: Cusco

imaginario personal y agregaríamos algo a las teorías de la conducta humana. Quizá veríamos que el deseo de dinero y de reconocimiento no son, como se cree hoy, las únicas fuentes de motivación de los seres humanos. Nos daríamos cuenta que ellas son infinitas, tantas como utopías podamos albergar en nuestro interior.

\section{Utopías colectivas}

Son aquellas que tienen su sustento en los sueños colectivos, en deseos que son comunes a más de una persona. Podemos identificar tres de ellos.

1. Utopias colectivas básicas. Es obvio que el ser humano es un ser social y que nuestra individualidad es relativa con respecto al resto, es decir, somos lo que somos en la medida que interactuamos con el resto. Además de las utopías individuales ya mencionadas también existen las utopías colectivas básicas o, para entenderlo más cercanamente, familiares. Por familia entendemos una unidad básica humana que permite la reproducción de la especie ${ }^{2}$. Pero hemos de señalar que, como muchos sabemos, existen muy distintos modos de configurarse. Larga sería la lista de la clasificación antropológica que nos revelaría que, en cada pueblo, cada cultura, se da un diferente tipo de conformación familiar que no es como nosotros la conocemos. Cada una de esas unidades tendría su propia utopía, producto de la historia personal de los cabezas de familia, la cual es transmitida en forma de

2 http://www.monografias.com/trabajos/antrofamilia/antrofamilia.shtml mandato a los hijos. Como suponemos, cada familia tendrá su historia, sus sueños, sus ambiciones, frustraciones y tragedias, y son esos hechos los que van a decidir las orientaciones, afectos, pasiones y ambiciones de los descendientes.

2. Utopias colectivas intermedias. Son aquellas que pertenecen a un determinado grupo humano unido por vínculos extra familiares como pueden ser: la religión, el idioma, el territorio, las posesiones, las creencias socio-políticas, las tragedias, el éxito y muchos otros más. Pero este grupo puede estar conformado por unidades homogéneas, como, por ejemplo, una tribu, o por heterogéneas. En este caso, distintas naciones, culturas, razas, comunidades idiomáticas o religiosas pueden convivir dentro de un mismo Estado identificándose como clubes, partidos políticos, movimientos religiosos, barrios, ciudades, comunidades, etc. Además pueden existir instituciones de ricos y de pobres, de poderosos y de desplazados, de nacionalistas y de extranjerizantes, etc. La lista es aún más extensa y variable. Pero si algo los une, a pesar de sus notorias diferencias, es que todos comparten algún tipo de utopía originada por la particular historia y vicisitudes que han tenido en común. Por ejemplo, la nación judía, esparcida por todo el mundo, comparte la utopía de la 'Tierra Prometida'; la gitana, su iconoclasta filosofía de vida y la andina, su afán de reivindicación.

3. Utopías colectivas mayores. Aquí estarían las grandes utopías que abarcan ámbitos humanos más extensos 
que los antes citados. Es común denominarlas como utopías "de la humanidad", por ejemplo: el poder volar, la eliminación de las enfermedades, la vida eterna, el acceder directamente "al Creador" por propia evolución, la conquista del universo a través de la ciencia y muchas más. A todas las podríamos llamar mega-utopías. Pero si bien pueda que no toda la humanidad las comparta, actualmente, por efecto de la globalización (que nosotros preferiríamos llamar "occidentalización forzada") ya se encuentran difundidas por toda la tierra.

Todas las utopías colectivas tienen en común el sueño colectivo ${ }^{3}$. El sueño colectivo es el resultado, la sumatoria, de las necesidades y ambiciones de una agrupación o sociedad determinada. El sueño colectivo es el motor de las distintas humanidades. Detrás de él se generan todas las expectativas de la existencia: las económicas, las políticas, las religiosas, las artísticas. Puede que el ser humano no sepa quién es y a dónde va, pero sí puede querer ir a algún lado, aunque este sea el peor de todos y él lo ignore. Podríamos decir que las sociedades son como organismos que nacen, crecen y mueren; y que en cada momento de sus existencias se presentan nuevos retos que alcanzar, nuevos deseos por satisfacer, nuevos hambres que calmar. Todas estas ansiedades se traducen y se plasman en los sueńos colectivos. Pero el cómo brotan estos sueños es difícil de decir. Sabemos que existen, que aparecieron alguna vez. En algunos casos atribuimos su origen a lo divino, a los (remotos) antepasados, a algún hecho extraordinario o a un hombre ejemplar. Pero una vez que surgen son imposibles de erradicar. Existen imperativamente, o sea, nos empujan, querámoslo o no. Sin embargo, puede que estos sueños estén reprimidos, en estado de latencia, y por mucho tiempo. Quizá algunos factores impidan sus desencadenamientos como pueden ser: el estar sometidos o sojuzgados a los sueños colectivos de otra sociedad o la falta de un discurso utópico que los haga viables. Pero cuando estos factores son superados o resueltos es ahí cuando se plasma aquello que conocemos como la utopía.

Si pudiésemos observar cada sociedad que existe o haya existido veremos que a todas ellas les es común algún tipo de utopía. Puede que unas hagan más énfasis en lo económico, otras en lo religioso o en lo político, pero ello solamente es la forma cómo se sustentan; dicho de otro modo, cómo explican la utopía. Sin embargo, todas las utopías dan respuestas y soluciones a las inquietudes, temores y deseos de su sociedad. Hasta

3 http://www.unavarra.es/puresoc/pdfs/c_ponencias/Cabrera.pdf puede sonar irónico pensar que una sociedad que no viva una utopía resultaría siendo "utópica", en el sentido de imposible. Es posible que una sociedad haya logrado en algún momento realizar una determinada utopía, como en los casos del Renacimiento europeo, de la Revolución Industrial, o la fundación del país de Israel. Pero una vez hecho esto automáticamente debe iniciarse un nuevo proceso de utopización pues se corre el peligro de caer en la decadencia, tal como le ocurrió a la Roma de los últimos tiempos del imperio a la que le tuvo que llegar un ajeno cristianismo para rescatarla, aunque ya nunca volvió a ser lo que fue. Un fenómeno parecido estaríamos viviendo hoy con el capitalismo el cual, luego de haber conseguido concretarse, no ha podido hasta ahora generar otra utopía dentro de sí, trayendo esto como consecuencia la llamada crisis de la posmodernidad que no es otra cosa que la búsqueda indiscriminada de nuevas utopías que seguir (o en las cuales creer o soñar).

\section{El discurso utópico}

El discurso utópico vendría a ser la forma semántica como se plasma una utopía. Se trata de palabras y conceptos concatenados con cierta lógica adecuada al contexto en el cual se desenvuelven. Este discurso puede ser oral, escrito o incluso inconsciente, a modo de lejano recuerdo o deseo. Pero hay que aclarar que no toda fantasía, proyecto o locura tienen la facultad de convertirse en discurso utópico.

\section{Requisitos para reconocer un discurso utópico}

No por hacer una bonita y coherente narración, basada en un sueño, deseo o ambición, esta va a transformarse en una utopía. Detectar cuándo estamos ante una verdadera exigiría proponer ciertos requisitos metodológicos. A modo de sugerencia proponemos los siguientes:

1. Interpretabilidad. En principio, todo discurso que pretenda ser utópico debe referirse e interpretar en esencia el sueño colectivo de un grupo humano.

2. Integralidad. El discurso debe ser integral, debe abarcar todos los aspectos que conforman el ethos de la sociedad. Tienen que ser mencionados los aspectos económicos, políticos, religiosos, sociales, familiares así como aspectos más subjetivos: la felicidad, el futuro, etc. No debe quedar nada sin involucrar.

3. Solucionabilidad. El discurso debe proponer afirmativamente una solución para cada uno de 


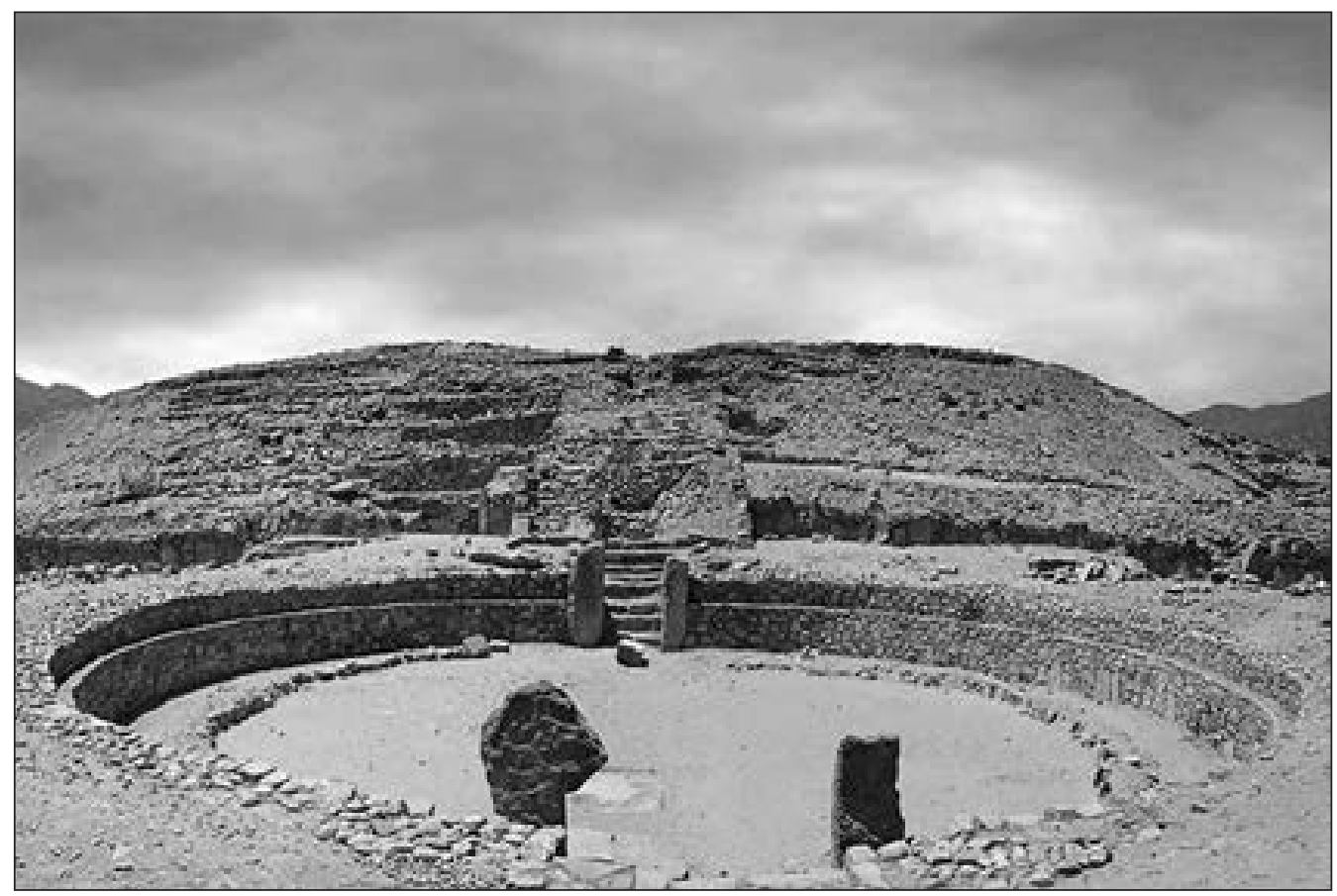

Caral (cinco mil ańos de antiguedad)

los problemas antes mencionados. Ellas deben ser concluyentes, por muy fantásticas que puedan parecer.

4. Ultraidad. El discurso debe llegar hasta el límite del cual ya nada más se pueda desear o esperar, es decir, debe satisfacer total y completamente todas las expectativas de la sociedad, sin dejar lugar a que pueda surgir algo más.

5. Realizabilidad. Debe tener un cierto sustento coherente y lógico, dentro del contexto específico de cada sociedad, de modo que se pueda demostrar que, de resolverse todos los inconvenientes que impiden su realización, sí es posible materializarse.

6. Oportunidad. El discurso debe estar estructurado en concordancia a un momento coyuntural que lo pueda seguir alimentando. Quiere decir que debe estar actualizado para que sea comprensible y aceptable.

\section{Fuentes de las utopías}

Como hemos dicho, las utopías son discursos que reflejan los sueños colectivos de las sociedades. Pero esos sueños tienen un sustento, un origen conceptual del cual parten. Haremos un intento por identificar estos posibles orígenes:

1. Las religiones. Son por esencia fuentes inagotables de utopías que se van reelaborando con el tiempo.
2. Mitos, leyendas y cuentos. Ninguna sociedad carece de ellos, siendo estas las fuentes más comunes e inmediatas sobre las que se construyen las utopías.

3. Las creaciones particulares. Las utopías pueden emerger de la inspiración de alguna persona, como el caso de Moro, aunque luego, con el tiempo, van adquiriendo carácter colectivo, modificándose de generación en generación. Es característica de ellas el no ser cercanamente realizables.

4. Los proyectos o paradigmas. Son ideas posibles de realizarse. Podría decirse que son intuiciones sobre hechos o fenómenos sociales próximos a suceder o que parecen estar por venir. Su difusión hace que se piense, se sienta más cercana su materialización, como sucede con la ciencia y tecnología en la utopía modernista.

En realidad, todas las fuentes están relacionadas y concatenadas y entre todas ellas se retroalimentan. Las diferencias estarían entonces solo en la forma semántica como se presentan, es decir, una utopía puede ser presentada como un serio proyecto creado por un profeta el cual, a su vez, refleja la voluntad divina adquiriendo así una forma religiosa. Pero dentro del discurso se encuentra una vieja leyenda popular que ha sido numerosas veces reelaborada por la colectividad. Están de este modo presentes las cuatro fuentes antes mencionadas: una religión fundada, una leyenda, un profeta-creador y un paradigma futuro. En muchas utopías vamos a descubrir que esto es una constante. 


\section{Clases de utopías}

Tomando como base las cuatro fuentes descritas proponemos cinco clases de utopías:

1. Utopias misticas. Aquellas que tienen su origen en una revelación divina y que conllevan una promesa futura. Algunas de las más conocidas son:

a) Las que forman las bases de las religiones. Tales como las de origen bíblico, las de origen indio (de la India) y en general todas aquellas en donde el elemento divino tiene la más importante participación. En ellas hay una promesa, un mañana, un futuro que de todos modos llegará. La Tierra Prometida o el Nirvana son un ejemplo de ello.

b) Los milenarismos o quiliasmos 4 . Están basados en los simbólicos plazos (como los mil años establecidos por la Biblia, de lo cual proviene la palabra) tomando esto al pie de la letra. Plantean una cercana intervención de un dios en el destino humano para lo que hay que prepararse. Son llamados también salvacionismos 5 . Aquí se encuentran innumerables sectas quiliásticas (del griego quilios, mil) que sucesivamente van apareciendo en todo lugar donde existe la presencia de la cultura occidental.

c) Los mesianismos. Muy vinculados al milenarismo. La diferencia es que aquí se cuenta con la presencia de un elegido, un iluminado, un profeta o mesías ${ }^{6}$ (de ahí la palabra) cuya presencia es indispensable para la realización de la promesa. Mayormente estos movimientos desaparecen con la muerte del líder.

d) En general todos los experimentos o intentos de hacer realidad en la Tierra aquellos principios o ideales que cada movimiento espiritual plantea. Ejemplos de ello serían los llamados cuáqueros de Norteamérica, las misiones jesuíticas que se establecieron en el Paraguay, la Florencia de Savonarola y, más cercanamente, la secta de los Israelitas en el Perú7. Podríamos incluir una "versión moderna" de utopías místicas: los movimientos de Nueva Era, los cuales

4 http://es.wikipedia.org/wiki/Milenarismo

5 El concepto salvacionismo, si bien está identificado con el llamado Ejército de Salvación, abarca todas las doctrinas que prometen una liberación de una falta, pecado o mal a través de una ritualidad.

6 http://es.wikipedia.org/wiki/Mes\%C3\%ADas

7 http://www.prolades.com/cra/regions/sam/per/israelitas-scott.pdf recogen todo tipo de manifestaciones de todas las épocas y culturas, dándoles una renovada vigencia. Aquí la lista es interminable pues va desde las más antiguas manifestaciones religiosas humanas, como el panteísmo (lo cual parecería indicar que ninguna utopía muere realmente), hasta sintetizaciones provenientes de los más avanzados descubrimientos y teorías científicas (como, por ejemplo, aquellos que afirman que existen universos paralelos con los cuales nos podemos comunicar y hacia donde nos dirigimos en el momento de la muerte).

2. Utopias fantásticas. Tienen su origen fundamentalmente en mitos, leyendas, relatos y creencias populares y no se encuentran organizadas ni orientadas con algún fin. Algunos ejemplos son: el continente hundido de Atlántida, la isla Brasil (Breasail), el país del Preste Juan, el de Ofir, el de Cocaña, la tierra de Nunca Jamás, la Isla de San Anselmo, Vinlandia, La Svolderdie, Vineta, Rungholt, Dabayde, la Gran Noticia, Las Minas de Esmeraldas, La laguna del Sol, el Reino del Sol, Traspalanda, el mito tupi-guaraní de la Tierra sin Mal. A esta relación se les unen las versiones modernas como el extraterrestrismo (donde los extraterrestres son ángeles o enviados divinos que vienen a ayudarnos y a llevarnos a su celestial galaxia; ejemplos de ello son el libro Yo visité Ganimedes y la película Cocoon). En el contexto andino tenemos los casos de El Paititi y El Dorado.

3. Utopias literarias. En su mayoría se trata de creaciones de autores conocidos y son esfuerzos por alcanzar y/o sugerir un ideal de sociedad, en muchos casos, planificada, equitativa y con la intervención vertical e imprescindible del Estado. Algunos ejemplos son: La República de Platón, la consabida Utopia de Tomás Moro, la obra de Joaquín de Fiori y sus tres edades de la tierra, la novela Shan-gri-lá y numerosas más. Pero tal vez uno de los libros que más ha movilizado la imaginación y despertado al mundo occidental en todos los terrenos sea Los comentarios reales de los Incas del peruano Garcilaso de la Vega. La repercusión que tuvo en la historia quizá no ha sido aún aquilatada en su verdadera magnitud. Su fuerza radica en que demostraba que la felicidad en esta tierra sí era posible y no algo inalcanzable, propio del más allá, ya que los incas del Perú sí la habían logrado. De esta obra fundamental se desprenden otras como: La Ciudad del Sol de Campanella, La Nueva Atlántida de Bacon, el Código de la naturaleza de Morelly, Alzira 
de Voltaire, Los trabajos de Persiles y Segismunda de Cervantes, La Aurora de Copacabana de Calderón de la Barca, Las amazonas en las Indias de Tirso de Molina, a las que se suman otras de Montesquieu, Marmontel y Jacobo Rosseau. Más recientemente encontramos el conocido trabajo de Louis Baudin El imperio socialista de los Incas.

Debemos hacer notar que en el virreinato del Perú, en la época del virrey Toledo, los españoles fomentaron la difusión de la obra de Sarmiento de Gamboa Historia indica con la que pretendían justificar la Conquista. Esta era la versión "oficial" que debía ser aceptada por los "indígenas", en contraposición a los Comentarios reales. Mas, de estas dos fórmulas utópicas, solo esta última prosperó, al punto de que durante todos estos siglos, y hasta el día de hoy, sigue siendo la utopía andina por excelencia. La Nueva crónica y buen gobierno de Huamán Poma de Ayala es otra obra importante que acompaña y complementa a la anterior. Igualmente podríamos incluir aquí otro discurso utópico en forma de teatro popular, pero que no posee autor conocido: el taki, una expresión quechua que significa canto, música y representación. Este suele durar días y en él participa toda la población, incluso los visitantes. En su mayor parte hace referencia al Imperio de los Incas, a la captura de Atahualpa y a un pronto retorno de ese Imperio. Esto se mezcla con la noción andina del retorno, dentro de una concepción cíclica de la vida, que en quechua es llamado pachacuti. Agregaríamos también las numerosas obras literarias orales que mencionan estos temas (la poesía, los cuentos, leyendas y la música andina). Por último incluiríamos también aquellos experimentos sociales que, teniendo sustento en una expresión literaria no religiosa, trataron de ser realizados en distintas épocas como los Hospitales de Vasco de Quiroga ${ }^{8}$ en México y las Granjas Colectivas propugnadas por el pensador francés Saint Simon, como parte de lo que se llamó el socialismo utópico?.

4. Utopías históricas. Estas se basan en el resurgimiento de algún glorioso pasado, idealizándolo, mitificándolo y pretendiendo reconstruirlo. Su objetivo es rescatarlo bajo el criterio de que fue mejor. De esta clase son: el Paraíso perdido, la Edad de oro, el Humanismo (que dio origen al Renacimiento), el país de Israel, el Nuevo Imperio Romano de Mussolini, el imperio Khmer de Pol Pot y, en general, todo movimiento que apunte a resucitar el orden antiguo. En el caso del mundo andino se dan numerosas expresiones de la utopía incaísta como son: el Inkarri, Adaneva, el taki unquy, el pachakuti $y$, sobre todo, el Indigenismo, aunque creemos que sería más apropiado llamarle Incaísmo puesto que fundamentalmente apunta a reconstruir un modelo netamente incaico mas no las vivencias y valores actuales de los múltiples pueblos de los Andes. La utopía incaísta nació en el mismo momento de la Conquista, encarnándose en Manco Inca, y ha pervivido a lo largo de toda su historia, a tal punto que forma parte de la idiosincrasia del Perú tenerlo siempre presente en todo acontecimiento nacional. De una interminable relación de personajes que lo han utilizado como bandera para sus causas hacemos solo una reseña: Túpac Amaru I, Calixto Túpac Inca, Juan Choqne, Juan Santos Atahualpa, Túpac Amaru II, Andrés Avelino Cáceres y Antonio Laymes, Rumi Maqui, La Confederación PeruanoBoliviana, Gabriel Aguilar y Juan Manuel Ubalde, El Movimiento Tahuantinsuyo (con Ezequiel Urviola, Hipólito Salazar, Eduardo Quispe y Quispe, Hipólito Pévez y Demetrio Sandovalez), el anarquismo con Manuel González Prada y, finalmente, vigente el día de hoy, el Consejo Indio de Sudamérica $(\mathrm{CISA})^{10}$, perteneciente al Consejo Indio de Pueblos Indígenas, avalado y protegido por la Naciones Unidas.

5. Utopias futuristas. En estas la idea fundamental es la creencia en el concepto de progreso, en vez del de repetición o vuelta a algún pasado. Presuponen que lo mejor está en el futuro, no como un tiempo que vendrá sino como la acumulación de todos los beneficios obtenidos en el pasado. Así lo fueron la Revolución Francesa, el Industrialismo en sus variantes Capitalista Liberal y Capitalista de Estado (o socialista-comunista). Igualmente, a través de la ciencia-ficción se nos muestran dos visiones utópicas: la pesimista, como las novelas 1984 de George Orwell, Un mundo feliz de Aldous Huxley, y las películas Metrópolis de Fritz Lang y El Planeta de los Simios; y la optimista como la película Viaje a las Estrellas y el libro La Tercera Ola de Alvin Tofler. En el mundo andino el desarrollismo o modernismo es una utopía reciente y convive con la utopía incaica. Básicamente lo propone como modelo a seguir y efectuar una imitación o un calco de Occidente para alcanzar "el desarrollo" como meta.

8 http://www.monografias.com/trabajos58/don-vasco-de-quiroga/donvasco-de-quiroga.shtml

9 http://www.filosofia.net/materiales/sofiafilia/hf/soff_u12_1.html

10 http://www.puebloindio.org/CISA/cisa.htm 


\section{Grados de realización utópica o facto-utopicidad}

Algunas utopías son posibles de realizarse y otras no. Podríamos decir que existen distintos grados de realización que clasificaríamos del siguiente modo:

1. Totalmente imposibles de realizarse. Son aquellas utopías que no pretenden salir del marco de lo hipotético pues, como el horizonte, siempre sirven para estar más allá de la realidad y, de ese modo, puedan funcionar mejor: el Paraíso Perdido, el Nirvana, el Cielo, la Edad de Oro, etc.

2. Realizadasy fracasadas. En algún momento se intentó llevarlas a la práctica y no resultaron, quedando marcadas, pero no necesariamente muertas. Pueden reaparecer cuando las circunstancias lo propicien: $L a$ República de Platón, la ultra religiosa Florencia de Savonarola, las misiones jesuíticas del Paraguay, los Hospitales de Vasco de Quiroga y el Comunismo.

3. Realizadas con éxito. Son aquellas que se llegaron a aplicar y funcionaron: la Revolución Francesa, el Renacimiento y el industrialismo en su versión capitalista.

4. Realizadas solo en parte. Aquellas que, a pesar de haber sido aplicadas tiempo atrás, aún siguen manteniendo la promesa de su realización: la vida religiosa en la tierra (el cristianismo militante a lo San Francisco de Asís), gran parte de los movimientos de Nueva Era y otros.

5. Utopias por realizar. Son aquellas que, sin haberse aplicado nunca, hasta ahora generan expectativas: son las utopías mesiánicas, de resurgimiento, como la andina-incaísta y otra parte de los movimientos de Nueva Era.

\section{Un comentario sobre la utopía industrialista}

La primera impresión que se tiene sobre el industrialismo es que, lejos de ser una utopía, se trata más bien de su antítesis, de algo totalmente opuesto a la utopía: una realidad dada. Para demostrar ello se apela al pragmatismo, aduciendo que no se parte de ninguna ideología sino solo del mundo de lo concreto, de lo real, de lo físico: el naturalismo. Se toma como criterio único al realismo científico en su versión tecnológica con la idea de que, por tratar con la materia, con los objetos, se piensa que se está tratando con la única verdad posible. Largo sería explicar la importancia del manejo de los conceptos razón, ciencia y tecnología en la conformación de esta forma de pensamiento. Sin embargo, esta argumentación no está exenta de objeciones.

Ya desde un inicio, con los griegos antiguos, se estableció la polémica entre los experimentalistas y los racionalistas; dicho de otra manera, entre los prácticos y

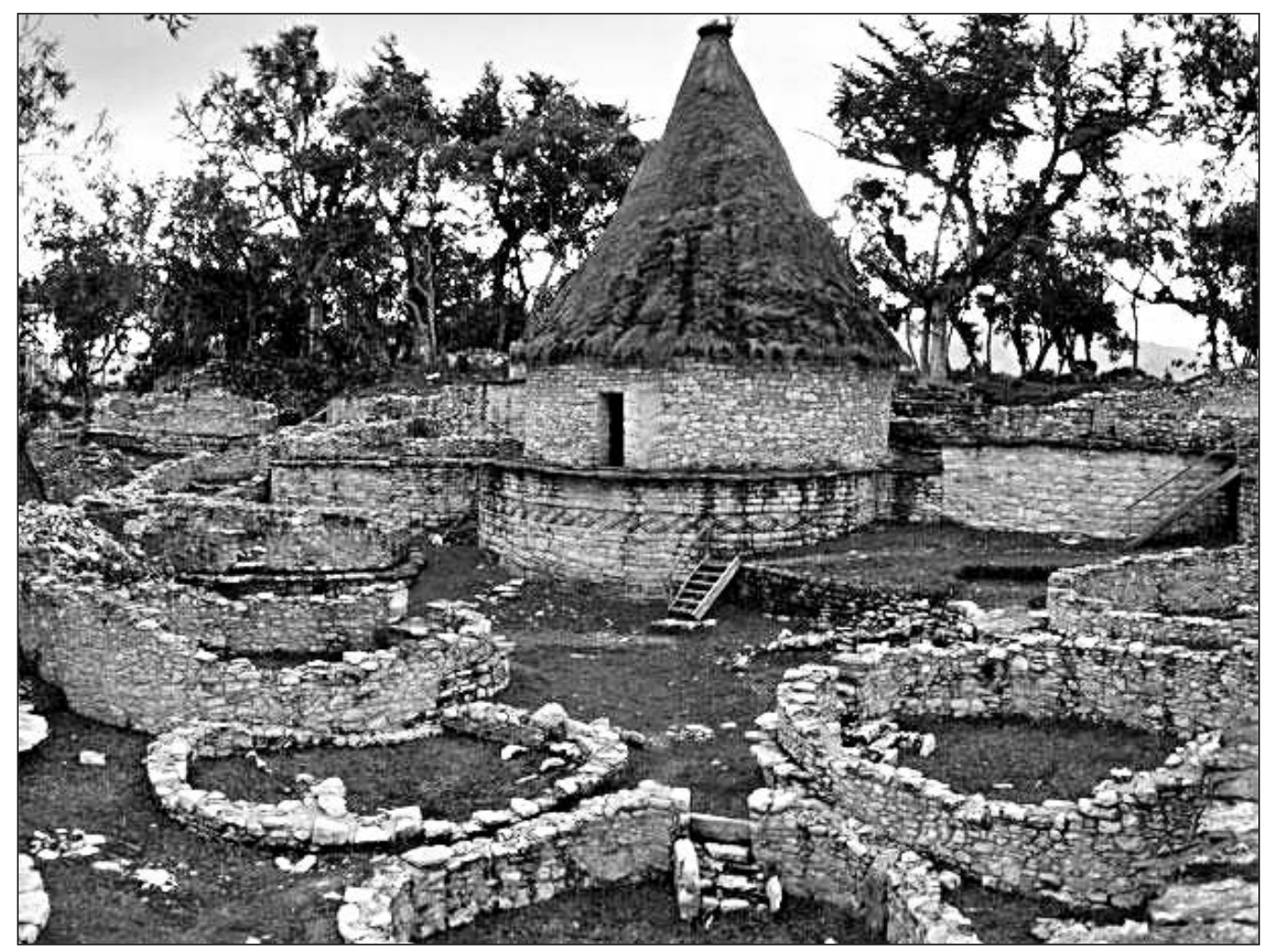

Kuelap (en los andes nororientales del Perú) 
los teóricos. La disputa platónica-aristotélica nos ilustra muy bien ese conflicto entre filósofos y científicos. Tiempo después Juan Bautista Vico recusaba a Descartes por haber creado un mundo de la razón que no necesariamente se ajustaba a la naturaleza sino a sus esquemas mentales. En nuestra opinión, la misma ciencia, en su devenir histórico, es una larga relación de afirmaciones y negaciones de lo afirmado hasta que, finalmente hoy, con la teoría cuántica, llegamos a dudar de que la naturaleza tenga una lógica determinada, o, al menos, tal como la quisiéramos entender.

Para el hombre común, todo ello ha terminado dando una sensación de fracaso pues lo que él esperaba, y esperará siempre, son respuestas definitivas a todas sus preguntas; y cuando estas no se dan, al igual que una criatura, llora, grita y se encapricha acusando de maldad a quien se las niega. Podría ser que en esto, en la sensación de fracaso al no tener las respuestas a todas las preguntas, radique la desilusión que el mundo occidental siente hacia esta ya realizada utopía industrialista. Por mucho que la ciencia avance, las demandas crecen con cada descubrimiento, con cada mejora, de modo que la insatisfacción es generada por lo mismo que buscaba saciarla, llegándose así a un callejón sin salida. Es por eso que pensamos que el Industrialismo, o el racionalismo o naturalismo, en su versión científica, es una utopía que, habiéndose realizado, ha perdido su carácter de sueño colectivo y, ahora, en vez de anhelarla, se la rechaza y se le imputa, quizá injustamente, de "fracasada" por no haber producido lo que podríamos llamar una especie de felicidad o algo parecido.

Toda utopía que llegara a concretarse parece que en la práctica tendría este mismo destino. Y es que da la impresión de que el mundo de los deseos y esperanzas, y temores tiene su propio camino en el hombre. Aquí es donde la ciencia encuentra su límite. El hambre del hombre es más voraz que sus logros; y mientras más lo satisface más crece. Aquí debería ingresar al debate la filosofía. Creemos que ella no puede perder su papel de analizadora del ser humano y no solo de su ciencia (con la metodología o epistemología), salvo que pensemos que el ser humano es solo su ciencia, con lo que entramos en el mismo terreno del cual queremos salir. Porque cierto es que la ciencia ha sido y es la escobita nueva del mundo occidental que se luce en cada ocasión y circunstancia. Pero de ahí a caer en el exceso de convertirla en un nuevo Dios porque, aunque no nos guste, eso es lo que creemos hoy, que es extralimitar el equilibrio de las cosas. Quizá necesitemos un poco más de madurez, algo más de tiempo para que este juguete-desarmador-de-todo no nos absorba tanto la vida y nos cause tantos desvelos. De que la ciencia sirve, claro que sirve. Pero no perdamos la óptica de las cosas: lo que realmente importa es para qué sirve. ¿A alguien le interesaría la ciencia si no sirviera para dar poder? Tal vez a muy pocos.

Lo que queremos decir es que el valor de la ciencia está hoy intrínsecamente ligado a su utilidad. Es en el 'para qué donde finalmente se ubican los problemas que realmente nos interesan. $Y$ ese 'para qué, insistimos, es el terreno de la filosofía. Si imaginariamente descubriéramos que la ciencia nos lleva inevitablemente a un despeñadero ¡alguien la querría? Tal vez dirán que eso no es cierto, que es pura fantasía. Pero ¿realmente no es cierto? porque lo que vemos actualmente no nos da mucha seguridad de nada, sobre todo si consideramos que, en lo que va de la historia del hombre, nunca nuestras armas han terminado oxidándose en sus depósitos (resulta aterrador pensar que, solamente el número de cabezas nucleares reconocidas oficialmente por Rusia y Estados Unidos asciende a cerca de treinta mil. ¿Cuántas más habrá extraoficialmente, sin contar otras terribles armas, como las bioquímicas?).

¿Podríamos afirmar que a partir de ahora cambiará la historia? ¿Ha madurado el hombre a la misma velocidad de su ciencia? Ojalá exista alguien que pueda asegurar que sí. Tal vez nos estamos saliendo un poco del tema, pero no podemos obviar la gravedad de la situación. Esto porque conocemos al hombre; porque nos conocemos. Cómo no pensar que en algún momento algo pasará y todo este castillo de naipes se va a venir abajo. Solo nos queda apostar por la filosofía, no por los economistas ni por los sociólogos ni por los políticos. Pero las dudas nos embargan. También después de la terrible Primera Guerra Mundial se creía firmemente que ya nunca más podría haber otra guerra como esa. $Y$ vino una peor. ¿Podrán los filósofos convencer a los poderosos, a los ambiciosos, a las transnacionales y a todos los que esperan su turno en el poder y que creen tener el derecho a disfrutarlo tan igual que sus antecesores? ¿Podrán convencer a China de que no siga creciendo y de que no piense que le ha llegado la hora de ser ella la hegemónica como todo chino espera y sueña? ¿Cómo se les va a convencer: con bombas? ¿Podrán igualmente convencer a los pobres del mundo que sigan esperando pacientemente su turno, que ya les llegará algún día su hora para disfrutar también ellos de los beneficios de la modernidad, mientras miran desesperados cómo otros se llevan a sus platos inmensas cantidades de todo lo que el mundo produce? ¿Qué entienden esos pobres de criterio, de cordura, de equilibrio, de ecología, de peligro atómico? 
Las pasiones humanas son fuego, y se está jugando con ellas. Urgentes son estas reflexiones y urgentes son las respuestas. Antes que ir a Marte tenemos que aprender a vivir en la Tierra. Volviendo a la esencia del Industrialismo, encontramos como sus postulados principales los siguientes:

- La satisfacción plena de las necesidades como objetivo de la vida.

- La economía como la razón de ser del ser humano.

- El mercado como el eje natural del desarrollo de la historia.

Podríamos decir que el principal problema de la utopía del industrialismo es que convierte al medio -la utilización de la naturaleza para la satisfacción de las necesidades- en un fin; y el fin, el ser humano, en un medio para alcanzar la utilización plena de la naturaleza. Entonces termina por cosificar a la vida y al hombre. Y viéndose el hombre como una cosa termina por ponerse al mismo nivel de ella. Es nuestra opinión que todo esto no es otra cosa que la proyección magnificada del pensamiento mercantil. Si observamos con la debida acuciosidad nos daremos cuenta que en todo hombre que se dedique al comercio se encuentran en sí los elementos que, a la larga, conformarán el cuerpo teórico del industrialismo capitalista.

- Una visión del hombre como ente que recurre a las cosas para vivir, tal como un vendedor ve a todos los que se acercan a su mercado: todos son clientes.

- De esto él deriva un modus vivendi universal: el consumo lo es todo.

- También se desprende todo un cuerpo de valores y de ética en función del consumo, lo cual determina un modus operandi que implica la unificación del mundo en torno a las reglas del mercado, con el correspondiente mecanismo que así lo asegure como lo es, la forma de gobierno liberal-democrático.

- Finalmente llega a la conformación del homo economicus, el hombre como sinónimo de "ser que busca satisfacer sus necesidades".
Vemos que en verdad no se ha inventado nada puesto que, lo que simplemente tenemos, es a un tipo de hombre dominante el comerciante, que ha impuesto su forma de ver el mundo al resto de la humanidad. Esto mismo lo han hecho en su momento los tipos humanos militar, religioso, artístico, pensador, campesino, nómada, cazador, etc. La utopía del industrialismo, al haberse materializado, ha dado a conocer tanto sus ventajas como sus desventajas. Como consecuencia de ello actualmente, en todo ámbito hasta donde proyecta su sombra, ocurre el mismo fenómeno: el desencanto. Existe la sensación de que esta visión unidimensional del hombre y de la vida es la causa de la desazón, de la inseguridad, de esa anomia que es la falta de futuro.

Porque, como decíamos al comienzo, si a una utopía no le sigue otra, llega la decadencia. Creemos que aún, a pesar de las voces optimistas como las del economista Nikola de Kondratiev ${ }^{11}$ - que justifica todo afirmando que se trata solo de una crisis parcial producto de una revolución tecnológica- las críticas son profundas. Hay quienes, para evitar el descalabro, plantean una actitud puritana: emplear la tecnología ultramoderna pero actuar con una moral conservadora, propia del Medioevo europeo. Sin embargo, por el otro lado se expresan los pesimistas que dicen: estamos en el postmodernismo ${ }^{12}$, el cual plantea la ausencia de fundamentos, parámetros, paradigmas, proyectos, metas y certezas absolutas, en fin: la ausencia de utopías. Pero también pensadores menos extremados buscan caminos alternativos como la ecología, la condonación de deudas y cambiar algo para que no cambie nada. De ahí sale lo de "darle un rostro humano" a la economía, pidiéndose que se "mire más al prójimo y menos a uno mismo" con lo que se plantea una contradicción con el principio fundamental de la sociedad industrial que es preferir al individuo antes que a la colectividad.

Digamos finalmente que esta crisis, esta des-utopización de la civilización occidental actual, aunque resulta muy estrepitosa y apocalíptica, aunque nos envuelva y nos convenza de su pesimismo, no es necesariamente la crisis de otras civilizaciones sino, muy por el contrario, una señal que nos avisa que nuevos mañanas, nuevas utopías

11 http://es.wikipedia.org/wiki/Nikol\%C3\%A1i_Kondr\%C3\%A1tiev 12 http://es.4truth.net/fourtruthespbnew.aspx?pageid=8589983633 
pueden venir, quizá, a través de esas civilizaciones. Desde este último punto de vista la noción utopía resultará entonces más compleja de lo que se piensa, al punto que no existe consenso entre los autores acerca de su correcta definición. Y esto quizá se deba a lo difícil de entender la interioridad del ser humano que hace que conceptos de una sola dimensión adquieran diversas al mismo tiempo.

Anotamos que, en este sentido, Occidente tiene serios problemas para asimilar tales procesos, dada la forma unidimensional y unívoca de su racionalidad. Esto quiere decir que, para entender a la naturaleza, la divide y particulariza en múltiples unidades, y así ordena ese todo al que ve como un "caos". Este es el origen de su ciencia. Por lo tanto, cada casillero del conocimiento debe tener su propio e inconfundible nombre y definición. De este modo conocer significa para esta forma de pensar armar un gigantesco rompecabezas compuesto de infinitas partes. Sin embargo, visto desde otro ángulo, existen cosas que solo podrían ser comprendidas multidimencionalmente, tal como lo efectúan muchos pensamientos no occidentales. Allí sí caben varias definiciones dentro de un mismo concepto, y esta es una forma de comprender a la naturaleza. En este caso no se trata de dividir para armar luego el rompecabezas, sino de entender los procesos en forma integral. No que una ciencia sea mejor que la otra.

Tampoco decimos que el pensamiento o la ciencia occidental sean más o menos verdaderos que la no occidental. Simplemente que para nosotros son caminos diferentes que cubren necesidades distintas. No dudamos que la ciencia occidental sea la más idónea para lo que significa el mundo moderno o contemporáneo puesto que ella misma ha surgido de esta realidad y es parte inherente de él. Por lo tanto, dentro de este contexto siempre será preferible utilizarla para todo fin. Pero en otros sistemas sí será necesario cambiar de formas de conocimiento y elegir aquellos más adecuados que respondan a esas otras exigencias.

Por poner un ejemplo sencillo: para desplazarse por la ciudad es mejor pensar occidentalmente, si no se quiere correr un grave peligro de muerte por accidente automovilístico. En cambio, si tenemos que cruzar la selva virgen del Brasil, será mejor que utilicemos la lógica, el conocimiento del nativo, si es que no queremos terminar como comida de caimanes o de insectos. Esto lo decimos con un poco de simplicidad pero el lector entenderá fácilmente nuestra intención al respecto: que cada realidad genera su propia cosmovisión y su correlativo conocimiento, el cual responde eficazmente a los retos que se presentan. Creemos que decir que el mal llamado "pensamiento primitivo" es un pensamiento pre-lógico o precientífico es insistir en ver el desarrollo de la humanidad a la manera Hegel-Kojeve-Fukuyama ${ }^{13}$ : como una línea de carrera subiendo hacia la sociedad liberal occidental. Para nosotros, insistimos, se trata de una forma paralela de ver y entender el mundo, que tiene un origen y un fin diferente al occidental, que no es parte de él.

Cierto es que una cultura puede asimilar a otra e incluir sus conocimientos en su propio bagaje, pero tal hecho no significa necesariamente que ese era su destino: ser absorbido. A este respecto preguntémonos qué hubiera pasado si la civilización occidental no hubiese subyugado a las otras. ¿Habrían estas alcanzado grados iguales o mayores de desarrollo material? ¿Dónde estarían hoy, por ejemplo, las culturas aztecas, incas, indias, chinas si no hubiesen intervenido los occidentales, frustrándoles su desarrollo natural? ¿Teme acaso Occidente que la respuesta no sea la que más le guste oír? ¿Teme acaso que, supongamos, descubra que hoy podrían estar viajando a otros planetas los descendientes de Cuauhtémoc, y con tecnologías más simples? Lamentablemente eso es algo que nunca se podrá comprobar, y que quedará como duda eterna y mea culpa para occidente saber qué hubiera pasado con todas estas culturas aniquiladas si no se les hubiese subyugado. Esta sola indemostrabilidad debería servir para que reflexionemos muy seriamente acerca de lo que actualmente entendemos, o queremos entender, acerca de lo que es la Historia. Quizá dejar de lado la soberbia sería el primer paso para resolver nuestros más importantes problemas. 